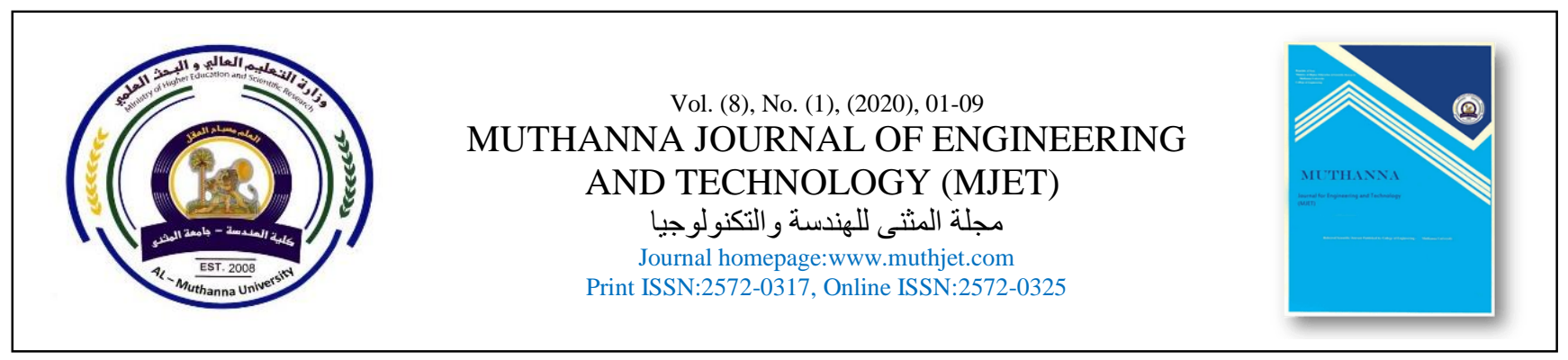

\title{
The Effect of the Spatial Organization Characteristics in Reducing the Crime in Al-Hila City
}

\author{
Ameera Jaleel Ahmed and Sabah Mohamed abd Mosehab \\ University of Babylon/ Faculty of Engineering/ Architecture Department
}

\section{ARTICLE INFO}

Received:22/11/2019

Accepted:22/07/2020

Keywords

$\overline{\text { Urban Environment, Spatial }}$ organization, Connectivity, Integration, control

\section{ABSTRACT}

The present work is about an organized crime which is considered a serious phenomenon that generally comes upon the world and especially in the Iraqi area. In recent decades, Al- Hilla City has suffered from spread variety of crimes, which lead the citizens to lack the sense of security. For this reason, it is seen it is significant to study this phenomenon with a new parallel phenomenon which causes their appearance. In addition, it is thought that this topic has not been tackled yet. The problem of the study lies in the lack of holistic scientific knowledge about the role of the synthetic properties of spatial organization for the city of Al- Hilla in crime growing. The study aims at establishing a holistic knowledge of that role. To deal with the problem of the research, an inductive approach (descriptive- analytical) has been adopted. The data is got from the responsible security institutions and is analyzed through invest the calculation method (space syntax).

The results of the research showed that there are four areas ((4 zones) where crime is concentrated in the city and the growth of crime is related to the change of the synthetic characteristics of spatial organization (Connectivity, control, and Integration) of urban space. On the other hand, the diversity of crime in urban areas is related to other parallel phenomena and not to the structural characteristics of urban space. 


\section{Introduction}

Since 2003 and so far, the city of Hilla has suffered from an increase in the number and variety of crimes, creating a feeling of insecurity among the local citizens. Therefore, it is necessary to study the phenomena parallel to the growth and diversity of these crimes within the local society, through extrapolating the reality of the situation of Iraqi cities. Today we ask the following questions: - Can the characteristics of spatial organization be a phenomenon parallel to the growth and diversity of crime within the city? What is its role in stimulating the growth and diversity of crime phenomenon? What are the characteristics of urban spaces which are characterized by the frequency and diversity of crime at the Comprehensive and local level of spatial organization? Can we, as urban designers, identify design indicators at the level of urban design related to the structural characteristics of space organization and contribute to reducing the growth and diversity of crime? Hence, the main research problem has been identified the lack of comprehensive scientific knowledge on the role of the structural characteristics of the Spatial organization of the city with the growth and diversity of crime. This requires highlighting and studying the problem. The secondary problem is also identified:

1- The existence of cognitive deficiencies in the role of changing synthetic characteristics of spatial organization (Connectivity, control, and Integration) of urban space locally and comprehensively by the growth of the crime phenomenon.

2- The existence of cognitive deficiencies in the role of changing the synthetic characteristics of spatial organization (Connectivity, control, and Integration) of urban space locally and comprehensively with the diversity of crimes and the degree of them

impact.

The main research hypothesis is determined that the growth and diversity of the crime are influenced by changing the synthetical characteristics of spatial organizations (at holistic and local levels). The secondary research hypothesis is defined as follows:
1- There is a positive relationship between the increase in the degree of synthetic characteristics (Connectivity, control, and Integration) of the spatial organization at the comprehensive and local level with the crime growth.

2- There is an inverse relationship between the increase in the degree of synthetic characteristics (connectivity, control, and Integration) of the spatial organization at the comprehensive and local level with the diversity of the crime phenomenon.

Based on identifying the research problems, the objectives of the research are as follows:

1- Revealing the nature of the relationship between the characteristics of Spatial organization (at holistic and local levels) and the growth as well as the diversity of crime phenomenon in the city of Hilla through the following:

- Determine the relationship between changing the holistic synthetic characteristics of Spatial organization (integration, control, and connectivity) as one of the characteristics of Spatial organization.

- Determine the relationship between changing the local synthetic characteristics of spatial organization (integration, control, and connectivity) as one of the characteristics of a spatial organization.

2- $\quad$ Attempting to reach indicators for the design of urban spaces (at holistic and local levels) in the city that contribute to protecting the security of citizens from crime by defining specifications for the structural characteristics based on the degree of integration, control and connectivity as 
one of the characteristics of space organization.

3- Investment of synthetic theories in determining the characteristics and criteria to raise the level of security performance of the urban environment in Hilla city.

In order to address the problem of research in accordance with the ideas and objectives of the research, an inductive approach is adopted (descriptive-analytical) and within two axes: -

1- The theoretical axis: -

- Collecting data from the security departments, the means of official advertising, and classifying crimes (the approved phenomenon) and distributing them to the city plan.

- Analyzing the previous studies on the topical and comprehensive structural characteristics of urban space, determining $\mathrm{g}$ the procedural definitions and the extracting the measurement indicators for independent phenomena (characteristics of Spatial organization) and dependent phenomena (crime growth in the city center)

2- The Practical axis: -

- Collecting information about the number and location of crimes and their classification and applying that on the scheme of the city.

- Examining the research hypotheses and electing the study case (areas in Hilla city) for their similar characteristics with many Iraqi cities and their suffering from the most serious and violent crimes during the last decade, and then analyzing these data through the use of the computational method (space syntax) and analyzing the structural properties of space (Integration and communication control) for the safest areas of the city and the most dangerous ones.
- Identifying the findings, conclusions, and recommendations by identifying strategies to address the urban areas where crime is concentrated in the city. The results of the research identified four areas where crime is concentrated at different levels (murder, terrorist operations, theft, and armed robbery).

The results of the research also show that the growth of crime is related to the low degree of integration, control, and connectivity within the holistic organization and the increase of these indicators at the local level. In addition, the diversity of crime in urban areas is linked to other parallel phenomena but not to the structural characteristics of urban space.

\section{3- Crime, security, and safety}

Crime is a complex phenomenon in which several parts overlap such as social, cultural, economic, political and characteristics of urban environmental factors. so no researcher can engage in comprehensive study, and it is difficult to determine the direct factors which impact on it, as well as, each crime type have a spatial characteristic. this study dealt with the relationship of Spatial organization characteristics and the crime, assuming to neutralize the rest of the other factors.

A. legally meaning of Crime: - The term crime comes from criminalizing or find guilty. It is an act issued by a person that the law shall establish criminal punishment for it. also It is a contrary act to the provisions of the criminal law established by the legislator. Furthermore, it is a behavior that forbids by the state for necessity and punishes the perpetrators (Meryem,2008, pp.2).

\section{B. the social meaning of Crime:}

- crime as a human phenomenon is to satisfy the human instinct in an unusual way, not followed by the ordinary human to satisfy the same instinct, due to the extraordinary circumstances that helped to influence the actor the moment of committing his crime. Also it is a violation of the sanctity of traditions, norms, and habits prevailing, which 
require prosecute and responsibility for the perpetrator of the crime. also it is any act (outside the rules of social behavior), or abstention that conflicts with values and ideas that settled in the social conscience. furthermore, it is a violation of the values and ideas that society sets for its members. the society determine what normal behavior and what deviant or criminal behavior is according to its values and standards (Meryem,2008, pp.3).

C- Crime meaning in planning: - means a selective phenomenon, attracted to the environment eligible and place of occurrence, when available in that environment elements and qualifications for the occurrence of crime where the environment loses security and safety (Jeffry, 1972, p. 31). Security in language means reassurance, which is the opposite of fear, the exclusion of fear, anxiety, and provide safety and tranquility,), but the term means the necessary condition for the growth and prosperity of social life, which is a prerequisite for the success of any aspect of human activity, agricultural, industrial or economic, but it is necessary to preserve the state entity and assert its independence (Al-Alawn \& Ammar, 2017, p. 81).

\section{4- literature review}

The urban environment is all the world around us encompasses everything we see or feel wherever we are and even what we cannot see, it is spatially connected with us (it is a series of physical structures and events), Studies that classified the environment into compounds are: -

1 - (Amos Rapoport, 1977) Study tagged with (Urban Design And Human Systems,) that the urban environment is a series of relationships between man and physical elements, and this relationship is at three levels, between elements and other elements, and between elements and man on the one hand, and between Man and man on the other, In his view, the set of relations formed by the environment is characterized by regularity and coordination, and has a form and structure, the environment is not a random organization, but subject to a pattern of space relations. (Rapoport 1977 / pp. 3-12) Through the characteristics of the relationship between man and physical elements, the nature and identity of the environment is determined and shown in a spatial form by expressing them in categories of organizations such as :

A. (Spatial organization), which is the relationship between urban space and space organization and he defined by (cognitive Schemes)

B. (meaning organization), comes with space organization and is the meaning of the masses and expressed by signals, colors and scale, and identified through (environmental codes) and (cultural cues).

C. (communication organization) is the relationship between individuals in the urban environment, i.e. social communication between them and defined through the concept of filters and lifestyle. (Rapaport 1977 / pp 8-12)

Space structure is formed by the way that the space components of different space systems and their relationship with each other and their meanings that differ from one place to another, which distinguishes an urban environment from another depending on the visual relationship between the parts, also between the part to part, and part to the all. (Rapaport, 1977, p: 15).

2- Kevin Lynch (1960) Study in his book (The Image of the City), he believes that the relationship between man and urban environment, is based that how to perceive the elements and components of the urban environment through a mental maps and cognitive schemes by the mental construction of the physical components of the urban environment represented by the five elements. (Lynch 1960 / pp 6-8). He considers that the structure of the urban environment is the spatial relations between the five elements (edges, path, district, landmarks, nodes), as well as distinctive activities. Spatial organization, according to Kevin Lynch's concept, represents the structure, this means the relationships between elements and human interaction in the urban environment.

3- (Hillier \& Harson, 1984) Study tagged with (The social logic of space): focused on the relationship between social variables and characteristics of Spatial Configuration. The study aimed to develop a method to describe and analyze the spatial organization characteristics through social variables that can be linked to it, and it is greatly influenced by mental and social variables to be an objective reflection of these variables. His approach is based on morphological analysis of the basic 
structural relationships of different space systems. The study confirmed that space has a social dimension and that society has a spatial component. In other words, the relationship between them is mutual, and that social relations are not the only ones involved in interaction but in fact are inherent in space systems. So, it was revealed that the structural properties of space structures correspond to social variables by two basic (Hillier \& Hanson 1984 p. 78-94):

A. (Symmetry - Asymmetry)

B. (Distributedness - Non-Distribuends) Bill

Hillier explained that the visual effects of architecture on social outcomes pass through the channel of spatial organization relationship with the natural co-presence of individuals through generating movement. The spatial organization produces basic patterns of meeting people and raising awareness and also generates the potential of meeting people. (Hillier, 1996, p. 96-197).

4- (Jane Jacobs 1961) study In her book (The Death and Life of Great American Cities), Jane Jacobs studied the security of the urban population of American cities as an important part of the city and solved the problem of safe space through three main advantages: (Jacobs, 1961, p: 32-35 )

A. There are clear boundaries between public and private space and property identification.

B. Observation of the streets Observed by the population and be the beginning and end of the streets dedicated to the task of effective to maintain the continuity of the flow of the population.

C. Activate of streets and sidewalks continuously in most of the daytime makes it safer

5- Newman Oscar's theory, he developed (Defensible Space theory1972), that an extension of Jacobs's theory, he focused on (territoriality) in his own model of defended space and focused more on the architectural design of a residential area than Jacobs' urban planning. In his theory based on the experimental study, he identified five vocabularies for achieving safe space: territoriality, natural observation, description or environmental visualization, environmental media, and space gradient. (Al-Alawn \& Ammar, 2017, p. 83)
6- (Ray Jeffrey THEORY / 1972) :- in his book ( Crime Prevention Through Environmental Design (CPTED)), $\mathrm{He}$ discusses crime prevention through street design, parks, and others. his theory based on the experimental psychology principles, and physical environment role in changing criminal behavior. In $2^{\text {nd }}$ edition of the book he expands his approach through adopted complex models in variable physical environments, and he studied the offender's behavior as individuals of the general public with mutual influences on each other. And he discussed the effects of the external and internal environment on the Criminals. He confirms the proper design and effective use of the built environment can lead to a reduction of fear and crime, improve life quality, and enhance social interaction between the inhabitants. (Al-Alawn \& Ammar, 2017, p. 83), (EUROPEAN COMMISION, 2007, PP.: 9).

7- European Standardization Committee, 2007: Defines the most The Committee identified the most important defensive characteristics of public urban spaces it include the basic principles that mentioned in appendix (D) of the (European Standardization Committee) on Safe Space Characteristics (EUROPEAN COMMISION, 2007, PP.: 9): -

A. belonging sense to the place increases the imagination of security and safety and avoids the creation of places that use temporary (railway stations, exchange points, etc.). so the lack of belonging sense causes more exposed to crime than others for crime.

B. Intensified Self - observation in the vitality of places is very important in crime prevention, through the diversity of uses and not to create abandoned areas through design, because vandalism and criminality are usually concentrated in these places, while clear public areas, prevent crime and increase security perception.

C. Provide electronic monitoring (TV., C, ... ..etc. )

D. It is necessary to connect public spaces with the outside world and not isolate them, because they lead to exclusion and It produces isolated areas.

E. Clear identification of public and private spaces makes it easy to manage and supervise. 
F. The planning of roads leading to homes and services should carry the concept of security and accessibility for all residents.

G. temporary arrangements (workplaces, roads Annuals, barriers, and temporary fences) lead to discomfort and create dangerous places. They must be placed next to the spaces used.

8- Study (Alwan and Ammar, 2017): in their study (The Role of Environmental Design in Maintaining Safety Cities-AL-Karada Region as a Case Study) they review theories and architectural studies which specialize in the city security; determined $7^{\text {th }}$ mechanisms of environmental design were based on a comprehensive concept and find appropriate solutions in dealing with the built environment and the study concluded the following mechanisms: (Al-Alawn \& Ammar, 2017, pp: 87-89)

A. Natural observation (providing security elements, displaying warning signs, signs of ownership of buildings, exploitation of floors, a view of the streets, public places, poor visibility from inside buildings, etc.)

B. Natural control access (visibility in the environment in terms of harmony between housing and its neighborhoods, signs of ownership and visitor orientation, transparency and afforestation, fences and multiple exit options, avoiding narrow path between buildings, avoiding single exit points while enhancing multiple exit options, enhancing visibility Good looking along the way

C. Enhancing territory (spatial organization of the urban environment, definition of effective spaces adjacent to its own living spaces, interest in the design of streets and the use of real and symbolic barriers, fencing, good paving, planting in accordance with the location and definition of space, the structural characteristics of space organization, space gradient)

D. land uses Blending (convergence, relevance, diversity, conjunction and integration)

E. Reducing crime generators (avoid negative space and avoid space neglect)

F. Enhanced illumination (homogeneity and integration between natural and industrial lighting, clear lines of vision, and lighting of hidden isolated areas)

G. Management and maintenance (preservation of buildings from vandalism, preservation of the image and good appearance of the city, the use of finishing materials consistent with the general context, periodic maintenance of the city, good management of the city, achieving social justice in the city Increase social relations, adapt the building and space elements in the city with the surrounding environment).

Hence we conclude that spatial organization is one of the parallel phenomena to the crime emergence, but the subject has not been dealt with in detail. spatial organization consists of two main aspects: -

1) The first relates to man as an act or reaction as a result of his interaction with the environment

2) The second relates to the built environment with its components at the level of: -

- Urban spaces with its diverse formal characteristics

- The structural relationships between these spaces and the link between the process of interaction between human and urban spaces that determine the nature of the urban environment.

The study will take the structural characteristics (integration, control, and connectivity) and their relationship to the human act which Represented by the crime growth and diversity in order to determine the synthetic characteristics of safe space.

\section{5- Practical axis}

\subsection{Case Study (Al- Hilla City)}

Al- Hilla City is one of the important historical Iraqi cities. Located south of Baghdad and align ancient Babylon city in the north, which is one of the most important ancient historical areas in the world. according to the 2015 census, it has a more than a million of the population (Al-Hali, 2009, pp. 1-10), (Al- Khazraji, 2009, pp.10-12), as in figure No.

(1-a).

Since 2004 and so far, the city has seen a variety and frequency of terrorist crimes, were killed hundreds of martyrs and wounded, as well as, great economic losses were caused. Recently These crimes have increased in 
patterns and variety in different locations of the city. The information was gathered from reliable security sources, and the official audio- visual media in the country.as shown in table No. (1).

\subsection{Synthetic properties of spatial organization}

To achieve the research goals; structural analysis tools were adopted through the use of possibilities space syntax theory. The theory is a calculation method to determine the digital weights of the space structure. these weights express the relative strength among the structure parts. It is a structural analysis method of spatial organization and it proves the numerical values of space relative to the strength of its relationship in the overall system. The method has developed a visual format to express those values by classifying to groups, according to their digital symmetry, each group is expressed with different line thickness. This method is published in the two sources (Bill Hillier \& Hanson, 1984) and (Bill Hillier, 1996) (Hillier \& Hanson, 1984,

p. 108-113) as follows: -

1- Integration: - the integration index crosses about the integration degree of space relationship relative to all other spaces in the axial map of spatial organization. It is a vital indicator of Strangers movement in the system.

2- Control: - This property indicates the chosen degree and local spread in the system, which space provided it for each adjacent space directly.

3- Connectivity: - Is an index to measure the spreading property in different from the control indicator. The aim is to measure the Permeability degree provided by space for adjacent spaces in the system. It is measured by the number of rings in which the axial space is involved in other axial space composition in the axial map. The permeability increases when the number of rings shared by space is increased. This index also an indicator of the space spread. (Arc view) software is supported. it is one of the GIS software programs developed by a number of researchers in order to benefit from its analytical capability of these three indicators.

\section{6- Results}

1- The results of the research show that terrorism and murder crimes focus in the city center (Zone No.1), whereas crimes varied are concentrated in (Zone No.4) and (Zone No.2) and (Zone No.3). See Figure No. (1)

2- Crimes are increasing with increasing the percentage of spaces that have low integration at the holistic level, whereas they are increasing when the percentage of urban spaces has high integration at local level. See Table No. (2).

3- To achieve more security and safety spaces; less than $(55 \%)$ of urban spaces in spatial organization; must be provided with high integrity at the holistic level. On the other hand, to achieve safer spaces at the local level must be provided more than $(60 \%)$ of urban spaces with high integrity Figure No. $(7,8)$.

4- Crimes are increasing with increasing the percentage of spaces which have high connectivity at the holistic and local level . See Table No. (3), also to achieve more security and safe spaces; more than $(20 \%$ ) of urban spaces in spatial organization, must be provided with high connectivity at holistic level, and more than (30\%) of spaces at the local level see Figure No. $(9,10)$

5- Crimes are increasing with increasing the percentage of spaces which have high control at the holistic and local level See Table No. (4), also to achieve more security and safety spaces; (30-75\%) of urban spaces in spatial organization, must be provided with high control at holistic level, and $(15-55 \%)$ of spaces at the local level see Figure No. $(11,12)$.

6- There was no indication of the relationship between the diversity of crime, and synthetic characteristics of spatial organization (integration, control, and connectivity).

\section{1- Conclusions}

1- synthetic characteristics of Spatial organization (integration, control, and connectivity) play an important role in crime grows at a holistic level, and the lower grades of these characteristics Contribute to the emergence more violent crimes such as mass murder and terrorism.

2- increase of synthetic characteristics (integration, control, and connectivity) degree in the spatial organization lead to increase the crimes. 
3- The diversity of crimes in urban space is unlinked to the structural characteristics (integration, control, and connectivity), but linked to other parallel phenomena to the crime (such as social problems, poverty, ignorance, Non- Homogeneity of social classes, as well as prevailing ideologies).

\section{8- Recommendations}

1- It is necessary to provide urban spaces have less depth, connectivity, and more control in the spatial organization at holistic level, through creating conformable movement and visual axes as well as more distribuends in the spatial organization.

2- It also provides deeper, more connectivity and fewer control spaces at the local level by creating conformable movement and visual axes and reducing their distribuends, furthermore increasing their control in the urban system in order to make them more ambiguous to outsiders and provides a high-security situation for residential areas.

\section{2- Sources}

1- Meryem, OUCHATER," Crime and its social dimensions-Drug crime as a model", Master Thesis,college of Literature, humanities Sciences, and Social Sciences, University of Tlemcen- Algeria,2008,URL1.

2- Jeffery, C. Ray " Crime Prevention Through Environmental Design " Sage Publications Inc. Beverly Hill - London , 1972

3- Al-Alawn , Dr.Huda Abdul-Sahib,\& Ammar Mohammed Abdul Majid," The Role of Environmental Design in Maintaining Safety Cities-AL-Karada Region as a Case Study", Association of Arab Universities Journal of Engineering Sciences, VOL24 NO.2,2017,PP.81-103

4- Rapoprot, A.: Human Aspect of Urban Form. Pergamon Press Inc Elmsford, NY (1977)

5- Lynch, K.: The Image of the City.: MIT Press Cambridge, MA (1960)

6- Hillier, bill and Hanson,Julienne,"The social logic of space" Cambridge University Press, 1984

7- Hillier,bill,"Space is the Machine:Aconfigurational theory of architecture, Cambridge University Press, 1996

8- Jacobs, Jane," The Death and Life of Great American Cities ", Vintage books a Division of \&Random House, new York, 1961.URL2.
9- Al-Hali, Yousef krkush, " Intellectual life of AlHilla City ", AL_Haidariya Library , Iraq, 1ST Edition, 2009.

10- Al-Khazraji, Majid Eabd Zaid Ahmad," Intellectual life of Al- Hilla City In the 7th and 8th centuries (601-800) AH ", Babylon Center for Cultural and Historical Studies, University of Babylon, 2009

11- EUROPEAN COMMISION , "PLANIFICACION DISEÑO URBANO YGESTION PARA ESPACIOS SEGUROS MANUAL", DIRECTORATE-GENERAL JUSTICE, FREEDOM AND SECURIT AGIS , Action SAFEPOLIS , 2006 - 2007

URL1:-

http://dspace.univ-

tlemcen.dz/handle/112/4309

URL2:-

https://www.buurtwijs.nl/sites/default/files/buurt wijs/bestanden/jane_jacobs_the_death_and_life of_great_american.pdf 
Ameera J. Ahmed, Sabah A. I Muthanna Journal of Engineering and Technology, 8-1-(2020) 01-09 